\title{
Analgesic Comparison of Propiram Fumarate with Pentazocine, Codeine, and Placebo in Postsurgical Pain
}

JAY S. FINCH, M.D. Ann Arbor, Mich.

$P^{\mathrm{s}}$ BOPIRAM fumarate is a new potent analgesic shown to be highly effective in various types of pain. ${ }^{1}$ In postoperative patients, Forrest et al. ${ }^{2}$ reported oral propiram to be about one tenth as potent as intramuscular morphine. Thus, an oral dose of $50 \mathrm{mg}$ propiram is approximately equivalent to $4 \mathrm{mg}$ intramuscular morphine.<smiles>CCC(=O)N(c1ccccn1)C(C)CN1CCCCC1</smiles>

The purpose of this study was to determine the safety and effectiveness (pain reliaf and duration) of $50 \mathrm{mg}$ propiram fumarate in a double-blind comparison using $50 \mathrm{mg}$ pentazocine hydrochloride, $60 \mathrm{mg}$ codeine sulfate, and placebo as controls.

\section{Material and Methods}

Subjects for this study were selected from among surgical patients of both sexes, 18 to 65 years of age, who com-

From the University Hospital, University of Michigan Medical Center, Ann Arbor, Mich. 48100. This study was supported in part from a grant from the Delbay Corporation and in part from departmental funds.

November-December 1980 plained of severe pain following a surgical procedure. The type of surgery varied from herniorrhaphies and cholecystectomies to hemorrhoidectomies and various orthopedic procedures. All patients complained of severe pain at the site of the operation and required a potent analgesic for symptom relief. A prestudy physical and laboratory examination (hematology, urinalysis, blood chemistry) were carried out to exclude those patients with severe liver and renal disease. Patients with known history of physical dependence on narcotics were excluded.

A washout period of at least 4 hours was required before empaneling patients who had previously received other analgesic, sedatives, tranquilizers, psychotropics, or antiinflammatory medications. Patients were then randomly assigned on a double-blind basis to take either of four preparations: $50 \mathrm{mg}$ propiram fumarate, $50 \mathrm{mg}$ pentazocine hydrochloride, $60 \mathrm{mg}$ codeine sulfate, and placebo. Randomization was in blocks of four. To achieve double blinding, pentazocine and codeine tablets were encapsulated, and matching placebo capsules were prepared. Also prepared were placebo tablets matching propiram fumarate. Patients assigned to the active medications received a tablet and a capsule, one of which was an active drug and the other a placebo. The placebo group received a placebo tablet and placebo capsule. Each patient was as- 
signed a treatment unit identified by the code number. Actual identity of the unit was sealed in an envelope and kept unopened during the clinical trial.

After postoperative drug administration, patients were interviewed by a trained nurse observer to evaluate the degree of pain relief and to elicit any adverse effects. Evaluations were done $1 / 2$ hour after drug administration and at hourly intervals thereafter up to 6 hours. At each observation period the degree of pain was evaluated as: $1=$ none; $2=$ mild; $3=$ moderate; and $4=$ severe. $A$ known analgesic was given if at the end of 2 hours the patient failed to obtain any relief. The pain intensity measurement at the time of remedication was arbitrarily assigned to the rest of the observation periods, provided the patient was not remedicated before 2 hours. Patients vomiting within 30 minutes after drug intake were, disqualified. Patients were awakened at each evaluation point if asleep. Side effects were listed only if directly observed or described by the patient. All patients were in the study for only one day, and observations were made after a single dose of the medication.

The analgesic effectiveness of propiram fumarate was determined by comparing the amount of pain reduction (the difference between the pain intensity at the specific period and the baseline pain) with those of the controls. The value obtained was referred to as the PID (pain intensity difference). Comparison of the mean PID value at each observation period was then carried out between the treatment groups to see if statistically significant differences existed. In addition, the SPID (sum of pain intensity difference) was calculated by summing up the PID values of several observation periods and by statistically comparing the results between groups. Further, the patients' need to be remedicated was compared between treatment groups.
The parameters age, height, weight, and time of remedication were analyzed via the Kruskal-Wallis test. If a significant $(P<0.10)$ treatment effect was found, treatments were compared pairwise via the Mann-Whitney $U$ test. The comparison of treatments according to the distribution of patients by sex, race (Caucasian vs. non-Caucasian), proportion remedicated, and presence of side effects was performed using Fisher's Exact Test (2 by 4). Pain scores and SPID were analyzed at each time point via a twofactor (treatment, initial pain severity) analysis of variance. If the treatment's main effect was significant $(P<0.10)$ and the two-factor interaction was nonsignificant $(P<0.10)$, then the overall treatment means were compared via Duncan's multiple range test.

\section{Results}

Demographics. There were 55 (28 male, 27 female) patients who successfully completed the study. They ranged in age from 20 to 61 years; mean height was $167.6 \mathrm{~cm}$ (range 152.4 to $190.0 \mathrm{~cm}$ ); and mean weight was $71.6 \mathrm{~kg}$ (range 79.4 to $108.8 \mathrm{~kg}$ ).

Efficacy. Mean pain scores over time are shown in Fig. 1. Propiram was favored over placebo at $2 \quad(P<0.05), 3(P<$ $0.01)$, and $4(P<0.05)$ hours, while pentazocine and codeine were favored over placebo only at 3 hours $(P<0.05)$ after drug administration. SPID scores (Table I) showed all active treatments significantly $(P<0.05)$ superior to placebo. No significant differences were noted between the active drugs. Patients requirements for remedication (Table II) showed propiram and pentazocine slightly favored over codeine but highly favored over placebo.

Adverse Effects. The most common side effects encountered were drowsiness, nausea, and dizziness. In the propiram fuma-

The Journal of Clinical Pharmacology 


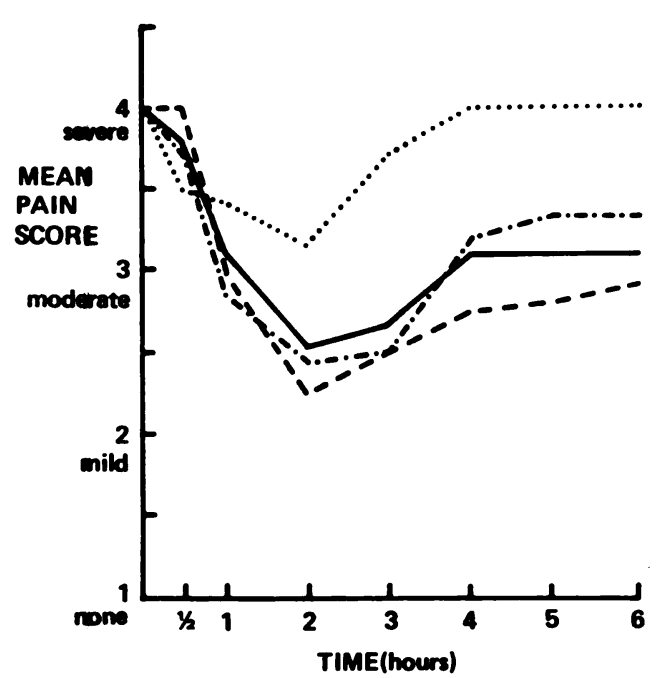

Fig. 1. Mean pain scores over time in patients with severe initial pain: (- $\longrightarrow$ propiram $50 \mathrm{mg}$; (- - -) codeine $60 \mathrm{mg}$; (._..-) pentarocine $50 \mathrm{mg} ;(\ldots \ldots)$ placebo $\mathrm{N}=$ 55).

rate group, one out of 16 ( 6 per cent) reported nausea, four of 16 (25 per cent) had drowsiness, and one of 16 (6 per cent) reported dizziness. In comparison, among pentazocine-treated patients, three of 13 (23 per cent) reported nausea, eight of 13 (61 per cent) reported drowsiness, and one of 13 ( 8 per cent) had dizziness. None of the codeine-treated patients reported nausea, but four of 14 (28 per cent) reported drowsiness and two of 14 (14 per cent) had dizziness. Interestingly, the ame type of side effects were encountered among the placebo-treated patients : two of 12 ( 16 per cent) had nausea, four of 12 ( 33 per cent) had drowsiness, but none was dizzy, although one patient on placebo developed vertigo.

\section{Discussion}

Propiram fumarate was shown to be effective in the treatment of severe pain following surgery as measured by subjective evaluation of pain relief. Its analgesic effectiveness was demonstrated to be statistically significant over placebo and equivalent to the active controls $-60 \mathrm{mg}$ codeine sulfate and $50 \mathrm{mg}$ pentazocine hydrochloride. Analgesia was most evident at the 2nd and 3rd hour after administration of propiram fumarate.

The time of remedication confirms these results. Since the need for remedication is contingent on a patient's failure to obtain adequate relief of pain from the initial treatment, the earlier the patient requires remedication, the less effective is the initial drug. Thus, on the basis of this criterion, Table II shows that propiram fumarate and pentazocine hydrochloride are both better than placebo and slightly better than codeine.

As anticipated, drowsiness and nausea were the most common side effects encountered in this study. However, there were no differences in incidence of side effects between the three active analgesics compared. No side effects required treatment.

\section{Summary}

The safety and effectiveness of a single oral dose of $50 \mathrm{mg}$ propiram fumarate as an analgesic was compared in a doubleblind clinical trial trial against single doses of standard reference analgesics (50 $\mathrm{mg}$ pentazocine hydrochloride or 60 mg codeine sulfate) or placebo. Subjects were adult patients experiencing severe

TABLE I

SPID scores

\begin{tabular}{lll}
\hline \multirow{2}{*}{$\begin{array}{c}\text { Treatment } \\
\text { group }\end{array}$} & \multicolumn{2}{c}{ Bevere pain } \\
\cline { 2 - 3 } & $\mathbf{4 h r}$ & $\mathbf{6 ~ h r}$ \\
\hline Propiram & 5.83 & 7.91 \\
Codeine & 5.28 & 7.00 \\
Pentazocine & 5.66 & 7.00 \\
Placebo & $\mathbf{2 . 7 1}$ & $\mathbf{8 . 7 1}$ \\
\hline
\end{tabular}

* Actives favored over placebo $(P<0.05)$ at 4 and 6 hours. 
FINCB

TABLE II

Patients Requiring Remedication

\begin{tabular}{lcccrrr}
\hline & \multicolumn{6}{c}{ Severe pain (\% patients)* } \\
\cline { 2 - 7 } Treatment group & $\mathbf{1 ~ h r}$ & $\mathbf{2 ~ h r}$ & $\mathbf{3 ~ h r}$ & $\mathbf{4 ~ h r}$ & $\mathbf{5 ~ h r}$ & $\mathbf{6 ~ h r}$ \\
\hline Propiram & 25 & 37 & 50 & 87 & 87 & 87 \\
Codeine & 35 & 57 & 71 & 100 & 100 & 100 \\
Pentazocine & 30 & 38 & 46 & 92 & 92 & 92 \\
Placebo & 41 & 66 & 83 & 100 & 100 & 100 \\
\hline
\end{tabular}

- Percentage figures are progressively cummulative at each subsequent time period.

postsurgical pain. Mean pain scores and SPID scores showed all three active drugs to be favored $(P<0.05)$ over placebo in patients with severe initial pain. The most common side effects seen were drowsiness, nausea, and dizziness. These were not severe enough to require treatment. Propiram fumarate $(50 \mathrm{mg}$ ) was shown to be an effective and safe analgesic in the treatment of severe postsurgical pain.

\section{Acknowledgments}

The author would like to thank Sara Ropasky, R.N., Darlene Uroda, R.N., and Linda Yonutas, R.N., for their assistance in this study.

\section{References}

1. Hullmann, R., Sommer, J., and Hoffmeister, F.: Propiram fumarate in a clinical study. Arzneimittel-Forsch. 24:718 (1974).

2. Forrest, W. H., Brown, C. R., Schrolf, $\mathbf{P}_{\text {, }}$ and Teutsch, G.: Relative potency of propiram and morphine for analgesia in man. J. Clin. Pharm. 12:440 (1972). 